\title{
ASSESSMENT OF THE DEMYELINATING PROCESS ACTIVITY IN PATIENTS WITH HERPESVIRAL MENINGITIS AND MENINGOENCEPHALITIS BASED ON THE LEVEL OF MYELIN BASIC PROTEIN (MBP) IN THE CEREBROSPINAL FLUID
}

D0I: 10.36740/WLek202103124

\author{
Anton V. Sokhan ${ }^{1}$, Yaroslava I. Burma', , Volodimir V. Pavlov², Oleksandr 0. Goidenko², Larisa I. Markush², \\ Hanna 0. Spitsyna ${ }^{3}$, Liudmyla V. Kolesnyk ${ }^{4}$ \\ ${ }^{1}$ KHARKIV NATIONAL MEDICAL UNIVERSITY, KHARKIV, UKRAINE \\ ${ }^{2}$ KHARKIV REGIONAL CLINICAL INFECTIOUS DISEASES HOSPITAL, KHARKIV, UKRAINE \\ ${ }^{3}$ NATIONAL AEROSPACE UNIVERSITY «KHARKIV AVIATION INSTITUTE», KHARKIV, UKRAINE \\ ${ }^{4}$ KHARKIV NATIONAL UNIVERSITY OF RADIO ELECTRONICS, KHARKIV, UKRAINE
}

\begin{abstract}
The aim: To study the peculiarities of demyelination by detection of changes in the levels of myelin basic protein (MBP) in CSF of patients with acute herpesviral meningitis (M) and meningoencephalitis (ME).

Materials and methods: A total of 136 CSF samples from 68 patients with herpesviral M and ME were collected. The control group consisted of patients with acute respiratory infection and meningismus. MBP level in CSF was identified at the admission and after 10-12 days of treatment. Analysis of MBP concentrations in CSF was performed using an enzyme immunoassay.

Results: Examination of patients on the first day of hospitalization showed the presence of a significant increase of MBP in the CSF in all patients with viral M/ME compared with the indicators of the comparison group $(p<0.01)$. In all groups of patients with ME, the level of MBP in CSF was significantly higher than the indicators of comparison group and $M$ groups of the suitable etiology of the disease $(p<0.01)$. In patients with lethal outcome, the MBP level was significantly higher $(p<0.01)$ than in all meningitis groups, but we did not find a significant difference with the patients with ME ( $p>0.05)$.

Conclusions: The increase of MBP level identified in patients with acute M/ME confirms the presence of the demyelinating process that occurs in all patients, but it is more pronounced in patients with ME.
\end{abstract}

KEY WORDS: herpesvirus, meningitis, meningoencephalitis, CSF, MBP, demyelination

\section{INTRODUCTION}

CNS infections make up a unique problem for physicians due to the rapid course of the disease, the high mortality rate and the complications they cause, as well as the inherent difficulties associated with diagnostics and treatment. These infections include meningitis (M) and meningoencephalitis (ME). They are usually characterized by high morbidity and mortality [1]. Acute $\mathrm{M}$ and ME rare_occur, compared to other infectious diseases - an average of 4-30 cases/100,000 population and 3-7 cases/100,000 population accordingly in developed countries and Europe each year, but mortality and economic losses are significant $[2,3]$. At present, in the developed countries and Europe, acute M/ ME in immunocompetent adults are more often caused by enteroviruses, herpesviruses, arboviruses $(70-90 \%$ of all cases of CNS infectious lesions) $[4,5]$. The highest mortality and severe course of disease are observed in herpesviral lesions of the nervous system [6].
The pathogenesis of brain damage during herpesvirus neuroinfection has not been sufficiently studied. The isolation of molecules, which localized solely in the cells of the nervous system - neuronal markers, was a significant impetus in the study of the pathogenesis of various neurological diseases. Determination of the content of these markers in the CSF or blood of the patient allows us to evaluate both the degree of damage of certain brain cells and the severity of the demyelinating process [7, 8]. Markers of CNS pathology are becoming increasingly important and are being investigated in acute and chronic diseases $[7,9]$.

Myelin basic protein (MBP) is considered the best marker for determining the activity of the demyelinating process [10]. MBP forms $30 \%$ of the myelin protein content and is the second most common protein of myelin sheath in the CNS. MBP is regarded as the "most important" myelin molecule due to its essential role in the formation of CNS myelin [11]. It was demonstrated that myelin degeneration 
Table I. Demographic and clinical characterization of the cohort

\begin{tabular}{|c|c|c|c|c|}
\hline Etiology of neuroinfection & $\begin{array}{c}\text { HSV-1,2 } \\
(n=20)\end{array}$ & $\begin{array}{c}\text { EBV } \\
(n=19)\end{array}$ & $\begin{array}{c}\text { VZV } \\
(n=15)\end{array}$ & $\begin{array}{l}\text { HHV-6 } \\
(n=14)\end{array}$ \\
\hline $\begin{array}{l}\text { Age in years } \\
\text { (Mean } \pm \text { SD) }\end{array}$ & $35.47 \pm 14.71$ & $36.43 \pm 16.09$ & $38.27 \pm 18.24$ & $31.69 \pm 13.03$ \\
\hline Sex, Men (n/\%) & $4 / 20.00$ & $7 / 36.84$ & $9 / 60.00$ & $8 / 57.14$ \\
\hline Sex, Women (n/\%) & $16 / 80.00$ & $12 / 63.16$ & $6 / 40.00$ & $6 / 42.86$ \\
\hline Meningitis (n/\%) & $15 / 75.00$ & $10 / 52.63$ & $11 / 73.33$ & $9 / 64.29$ \\
\hline Meningoencephalitis (n/\%) & $5 / 25.00$ & 9/47.37 & $4 / 26.67$ & $5 / 35.71$ \\
\hline Non survivors (n/\%) & $1 / 5.00$ & $2 / 10.53$ & $1 / 6.67$ & $1 / 7.14$ \\
\hline
\end{tabular}

occurs after CNS lesions such as chemical intoxication, brain injury and demyelinating diseases [12].

Determination of the neuronal markers level promotes to early diagnostics because significant changes in their concentration often occur earlier than those damages that can be detected by instrumental examination. In addition, the ability of assess of the severity of CNS lesions and prognosis of the disease course, monitoring of the treatment of patients with various nervous system diseases, such as Alzheimer's disease, Huntington's disease, brain injury, hypoxic conditions in newborns, strokes was proved [13-16].

Infection of the CNS with influenza virus induces longterm upregulation of MBP expression while decreasing the thickness of myelin sheaths surrounding axons in the cerebellum and hippocampus of influenza-recovered mice. Influenza infection may induce MBP expression by increasing proinflammatory cytokines without affecting oligodendrocyte viability [17]. The demyelinating process in patients with herpes virus neuroinfections remains uncertain.

\section{THE AIM}

To study the peculiarities of demyelination by detection of changes in the levels of myelin basic protein in CSF of patients with acute herpesviral meningitis and meningoencephalitis.

\section{MATERIALS AND METHODS}

Potential study participants were admitted in Kharkiv Regional Clinical Infectious Diseases Hospital (Kharkiv, Ukraine). The inclusion of patients in the research program conducted with the selection criteria. Inclusion criteria: clinical symptoms typical for acute $\mathrm{M}$ or ME, etiological confirmation of herpesviral etiology of disease by CSF PCR, age of patients - 18 to 65 years, voluntary consent of the patient to participate in the study. Patients were excluded in the following cases: the presence of comorbidities, which can influence the level of neurospecific proteins - HIV, Alzheimer's disease, multiple sclerosis, hematological diseases, malignant neoplasms.

68 patients with herpesvirus $\mathrm{M}$ or ME were involved to the research according to the selection criteria. Among them: 20 patients with herpes simplex virus 1,2 (HSV-1,2)
M/ME, 19 with Epstein-Barr viral M/ME, 15 with Varicella-Zoster M, 14 with Human herpesvirus 6 (HHV-6) M/ ME. The control group consisted of 15 patients with acute respiratory infection and meningismus.

At hospital admission, demographic data, clinical indicators were obtained from patients. Anamnesis of the disease, complains and neurological status were recorded briefly.

CSF was aspirated by lumbar puncture. Performing of lumbar puncture was in a line with the usual protocols of diagnostics and treatment of patients with signs of meningitis. Patients involved in the study were not subjected to additional invasive procedures. Collecting CSF in patients with ARI and meningismus performed only at the beginning of treatment to exclude neuroinfection. The CSF samples were immediately frozen at $-70^{\circ} \mathrm{C}$ until subsequent analysis. CSF MBP level were identified on admission and after 10-12 days of treatment. Analysis of MBP CSF concentrations was performed using an enzyme immunoassay based on the sandwich technique («AnshLabs», ELISA, USA) in Central scientific research laboratory of Kharkiv National Medical University. Work conducted in accordance with the Declaration of Helsinki. The study was approved by the ethics committee of Kharkiv National Medical University, Kharkiv, Ukraine. All data were analyzed using «BiostatPro», AnalystSoft Inc program. We used the Mann Whitney $\mathrm{U}$ test for continuous variables. $P$ value of $<0.05$ was used for significance.

\section{RESULTS}

The highest age was observed in patients with VZV meningitis - 38.27 \pm 18.24 years, the youngest - in patients with HHV-6 infection $31.69 \pm 13.03(\mathrm{P}<0.05)$ (table 1$)$.

The quantity of women and men was the same almost in all groups, however, among patients with HSV-1,2 neuroinfection, women significantly predominated -16 (80\%) of 20 cases. The most severe was EBV and HHV-6 neuroinfection, a severe course of the disease was observed in $47.37 \%$ and $35.71 \%$ of patients (table 1 ).

Severity of the condition of all patients with ME was caused by development of focal neurological symptoms and brain edema symptoms. In patients with EBV and HHV- 6 infection, symptoms of focal lesions of the brain in the form of paresis, paralysis and cognitive impairment were more common. Meningitis was observed in $15(75 \%)$ patients with 
Table II. MBP level in CSF of patients with acute herpesvirus meningitis and meningoencephalitis on the first day of hospitalization

\begin{tabular}{|c|c|c|c|}
\hline \multirow{2}{*}{ Etiology of neuroinfection } & \multicolumn{2}{|c|}{ MBP, ng/ml } & \multirow{2}{*}{$\mathbf{p}$} \\
\hline & Meningitis & Meningoencephalitis & \\
\hline HSV-1,2 & $4.41 \pm 0.511$ & $9.40 \pm 0.53^{1}$ & $p=0.0019$ \\
\hline VZV & $4.35 \pm 0.711$ & & \\
\hline EBV & $4.11 \pm 0.341$ & $11.05 \pm 1.32^{1}$ & $p=0.0001$ \\
\hline HHV-6 & $4.57 \pm 0.281$ & $13.30 \pm 0.99^{1}$ & $p=0.0001$ \\
\hline Control group & $2.13 \pm 0.15$ & & \\
\hline
\end{tabular}

Notes: $p$ - the level of significance of the difference between the indicators of patients with meningitis and meningoencephalitis of the same etiology, obtained using the Mann-Whitney test; ${ }^{1}$ - significant difference with comparison group metrics $(p<0.05)$.

Table III. MBP level in CSF in patients with acute bacterial and viral M /ME on the 10-12 day of hospitalization

\begin{tabular}{cccc}
\hline Etiology of the disease & \multicolumn{2}{c}{ MBP, ng/mI } & ME \\
\cline { 2 - 3 } & $\mathbf{M}$ & $8.29 \pm 0.27^{1}$ & $\mathrm{p}=0.0023$ \\
\hline HSV 1,2 & $6.37 \pm 0.34^{1,2}$ & & \\
\hline VZV & $4.52 \pm 0.21^{1}$ & $\mathrm{p}=0.0067$ \\
\hline EBV & $4.95 \pm 0.35^{1}$ & $8.56 \pm 0.70^{1,2}$ & $\mathrm{p}=0.0036$ \\
\hline HHV-6 & $5.22 \pm 0.38^{1}$ & $9.11 \pm 0.77^{1,2}$ & \\
\hline Comparison group & $2.13 \pm 0.15$ & &
\end{tabular}

Notes: $p$ - the level of significance of the difference between the indicators of patients with $M$ and ME of the same etiology, obtained using the Mann- Whitney test; ${ }^{1}$ - significant difference with comparison group metrics $(p<0,05){ }^{2}{ }^{2}$ - significant difference with the level of the first day of hospitalization $(p<0,05)$.

HSV-1,2 infection, in 10 (52.63\%) with EBV, in 11 (73.33\%) with VZV, in 9 (64.29\%) with HHV-6 etiology of the disease. The highest mortality was observed in patients with EBV (10.53\%) and HHV-6 (7.14\%) neuroinfection (table I).

On the first day of hospitalization the MBP content in patients with meningitis was equal to: at HSV 1,2 meningitis $-4.41 \pm 0.51 \mathrm{ng} / \mathrm{ml}$, at VZV meningitis $-4.35 \pm 0.71 \mathrm{ng} /$ $\mathrm{ml}$, with EBV meningitis $-4.11 \pm 0.34 \mathrm{ng} / \mathrm{ml}$, with HHV-6 meningitis $-4.57 \pm 0.28 \mathrm{ng} / \mathrm{ml}$, in the comparison group $2.13 \pm 0.15 \mathrm{ng} / \mathrm{ml}$ (table 2). In patients with ME, the MBP content on the first day of hospitalization was: at HSV $1,2 \mathrm{ME}-9.40 \pm 0.53 \mathrm{ng} / \mathrm{ml}$, EBV ME - $11.05 \pm 1.32 \mathrm{ng} / \mathrm{ml}$, HHV-6 ME - $13.30 \pm 0.99 \mathrm{ng} / \mathrm{ml}$ (Table II).

Thus, the MBP level in the CSF of all patients with herpes virus neuroinfection was significantly higher than the indicators of the comparison group $(\mathrm{p}<0.01)$. In all patients with ME, the MBP level in the CSF was higher than the indicators of comparison group and $\mathrm{M}$ groups of the corresponding etiology $(\mathrm{p}<0.01)$ (table 2$)$.

According to the received data, the MBP content on the 10-12 day of hospitalization in the CSF of patients with $\mathrm{M}$ was: at $\mathrm{HSV} 1,2 \mathrm{M}-6.37 \pm 0.34 \mathrm{ng} / \mathrm{ml}$, at VZV M $4.52 \pm 0.21 \mathrm{ng} / \mathrm{ml}$, at EBV M $-4.95 \pm 0.35 \mathrm{ng} / \mathrm{ml}$, at HHV- 6 $\mathrm{M}-5.22 \pm 0.38 \mathrm{ng} / \mathrm{ml}$ (table 3 ).

In patients with ME, the MBP content in the CSF on the 10-12 day of hospitalization was: for meningococcal infection - 10,48 $\pm 0,92 \mathrm{ng} / \mathrm{ml}$, pneumococcal $-11.63 \pm 0.74 \mathrm{ng} /$ $\mathrm{ml}$, HSV $1,2 \mathrm{ME}-8.29 \pm 0.27 \mathrm{ng} / \mathrm{ml}$, EBV ME $-8.56 \pm 1.40$ $\mathrm{ng} / \mathrm{ml}, \mathrm{HHV}-6 \mathrm{ME}-9.11 \pm 0.77 \mathrm{ng} / \mathrm{ml}$.

Thus, the direct dependence of the MBP level from the severity of CNS lesions remained on the 10-12 day of hos- pitalization. The highest levels of MBP were determined in patients with ME, but in all groups of patients with meningitis, the level of MBP remained significantly higher than the indicators of the comparison group (table III).

The level of MBP in the period of early convalescence was significantly reduced only in patients with HSV $1,2 \mathrm{M}$, and EBV, and HHV-6 ME compared with the indicators which were obtained on the first day of hospitalization.

\section{DISCUSSION}

In the mammalian CNS, oligodendrocytes constituting glial cells with microglia and astrocytes are myelin-forming cells [18]. It has been found that oligodendrocyte damage, which ultimately undergoes to apoptosis, to be responsible for myelin destruction and subsequent demyelination [19]. The detected changes of MBP levels indicate the presence of oligodendrocyte damage in patients with acute herpes virus M /ME. Such lesions are most pronounced in patients with ME, but they occur even in patients who do not have neurological symptoms.

The present results showed that demyelination commonly occurs in the brain of patients with herpesvirus CNS infection. Demyelination is a common feature in the brain that is infected by encephalitis viruses as seen in patients with HIV infection [20]. It is well known that free MBP causes a number of reactions: it changes the platelet shape, destroys cell membranes and acidic lipid vesicles, stimulates proliferation of astrocytes and Schwann cells and depolarizes the neural membrane [12]. The specific toxic effect of MBP on neurons at a concentration of $30 \mu \mathrm{g} / \mathrm{ml}$ 
and above has been proven [12]. MBP toxicity is due to the fact that this protein is an intrinsically nonstructural protein with a very positive charge [11], and upon release from the myelin cell membrane begins to interact with various molecules, including negatively charged lipids, sialic acids, polyanionic proteins, and neuron plasmas [12], which in turn causes inflammation and death of nerve cells [23]. Virus-mediated autoimmunity seen in multiple sclerosis and Theiler's virus infection was reported to cause $\mathrm{T}$ cell-mediated autoimmune disease related to demyelination [22]. The development of a myelin-specific autoimmune response may be a relatively important cause of demyelination in patients with Japanese encephalitis and other viral infections [23].

The limitations of our study do not answer the question of whether the development of demyelination in patients with herpesvirus neuroinfection is the result of direct cytopathic action of the virus or is it the result of immune responses. However, the dependence of the development of neurological symptoms from the degree of increase in the concentration of MBP in CSF in patients revealed us indicates about significant diagnostic and prognostic potential of this marker.

In addition, the MBP content in the CSF in patients with $\mathrm{M} / \mathrm{ME}$ in the early convalescence period is higher than the content in comparison group in all patients with herpes virus $\mathrm{M} / \mathrm{ME}$ (table 3 ). Such dynamics of the MBP level testify about presence of long-term disorders of myelin cells in the pathogenesis of herpesvirus $\mathrm{M} / \mathrm{ME}$, which are determined longer than the clinical manifestations of the disease.

\section{CONCLUSIONS}

The increase of MBP level determined in patients with acute $\mathrm{M} / \mathrm{ME}$ confirms the presence of the demyelinating process that occurs in all patients, but it is more pronounced in patients with ME. MBP release is one of the factors affecting of CNS tissues during acute herpesviral M/ ME. Demyelination may continue longer than the clinical manifestation of the disease.

\section{REFERENCES}

1. Parikh V., Tucci V., Galwankar $S$. Infections of the nervous system [published correction appears in Int J Crit IIIn Inj Sci. 2013 JanMar;3(1):97]. Int J Crit IIIn InjSci. 2012;2(2):82-97. doi:10.4103/22295151.97273.

2. George B.P, Schneider E.B., Venkatesan A. Encephalitis hospitalization rates and inpatient mortality in the United States, 2000-2010. PLoS One. 2014;9(9):e104169. doi:10.1371/journal.pone.0104169.

3. Oordt-Speets A.M., Bolijn R., van Hoorn R.C., et al. Global etiology of bacterial meningitis: A systematic review and meta-analysis. PLoS One. 2018;13(6):e0198772. doi:10.1371/journal.pone.0198772.

4. McIntyre P.B., O'Brien K.L., Greenwood B., Van de Beek D. Effect of vaccines on bacterial meningitis worldwide. Lancet. 2012;380(9854):17031711. doi: 10.1016/S0140-6736(12)61187-8.

5. Swanson P.A., McGavern D.B. Viral diseases of the central nervous system. Curr Opin Virol. 2015;11:44-54. doi:10.1016/j. coviro.2014.12.009.
6. Bloch K.C., Glaser C.A. Encephalitis Surveillance through the Emerging Infections Program, 1997-2010. Emerg Infect Dis. 2015;21(9):15621567. doi:10.3201/eid2109.150295.

7. Papa L., Robertson C.S., Wang K.K. et al. Biomarkers improve clinical outcome predictors of mortality following non-penetrating severe traumatic brain injury. Neurocrit Care. 2015;22(1):52-64. doi: 10.1007/ s12028-014-0028-2.

8. Mayer C.A., Brunkhorst R., Niessner M. et al. Blood levels of glial fibrillary acidic protein (GFAP) in patients with neurological diseases. PloS one. 2013;8(4):e62101. doi:10.1371/journal.pone.0062101.

9. Rees C.L., White C.M., Ascoli G.A. Neurochemical Markers in the Mammalian Brain: Structure, Roles in Synaptic Communication, and Pharmacological Relevance. Current Medicinal Chemistry. 2017;24(28), 3077-3103.

10. Brunkhorst R., Pfeilschifter W., Foerch C. et al. Astroglial Proteins as Diagnostic Markers of Acute Intracerebral Hemorrhage-Pathophysiological Background and Clinical Findings. Translational Stroke Research. 2010;1(4):246-51. doi: 10.1007/s12975-010-0040-6.

11. Harauz G., Ladizhansky V., Boggs J.M. Structural polymorphism and multifunctionality of myelin basic protein. Biochemistry. 2009;48:8094-8104.

12. Zhang J., Sun X., Zheng S. et al. Myelin Basic Protein Induces NeuronSpecific Toxicity by Directly Damaging the Neuronal Plasma Membrane. PLoS ONE. 2014;9(9):e108646. http://doi.org/10.1371/journal. pone.0108646.

13. RohlwinkU.K., Figaji A.A. Biomarkers of Brain Injury in Cerebral Infections. Clin Chem. 2014;60(6):823-34. doi: 10.1373/clinchem.2013.212472.

14. YokoboriS., Hosein K., Burks S. et al. Biomarkers for the clinical differential diagnosis in traumatic brain injury--a systematic review. CNS Neurosci Ther. 2013;19(8):556-565. doi:10.1111/cns.12127.

15. Vinther-Jensen T., Börnsen L., Budtz-Jørgensen E. et al. Selected CSF biomarkers indicate no evidence of early neuroinflammation in Huntington disease. Neurol Neuroimmunol Neuroinflamm. 2016;3(6):e287. doi:10.1212/NXI.0000000000000287.

16. Takano R., Misu T., Takahashi T. et al. Astrocytic damage is far more severe than demyelination in NMO: a clinical CSF biomarker study. Neurology. 2010;75(3):208-16. doi: 10.1212/WNL.0b013e3181e2414b.

17. Jin H. K., Ji E.Yu., Byung-Joon Ch., Sang-Soep N. Neonatal influenza virus infection affects myelination in influenza-recovered mouse brain. J Vet Sci. 2018; 19(6): 750-758. doi: 10.4142/jvs.2018.19.6.750.

18. Baumann N., Pham-Dinh D. Biology of oligodendrocyte and myelin in the mammalian central nervous system. Physiol Rev. 2001;81:871-927.

19. Zivadinov R., Zorzon M., Weinstock-Guttman B. et al. Epstein-Barr virus is associated with grey matter atrophy in multiple sclerosis. J Neurol Neurosurg Psychiatry. 2009;80:620-625. doi: 10.1136/ jnnp.2008.154906.

20. Stohlman S.A., Hinton D.R. Viral induced demyelination. Brain Pathol. 2001;11:92-106. doi: 10.1111/j.1750-3639.2001.tb00384.x.

21. Sun X, Wang X., Chen T. et al. Myelin activates FAK/Akt/NF-kappaB pathways and provokes CR3-dependent inflammatory response in murine system. PLoS One. 2010;5:e9380.

22. Grigoriadis N., Hadjigeorgiou G.M. Virus-mediated autoimmunity in multiple sclerosis. J Autoimmun Dis. 2006;3:1. doi: 10.1186/17402557-3-1.

23. Fazakerley J.K., Walker R. Virus demyelination. J Neurovirol. 2003;9:148-164.

ORCID and contributionship:

Anton V. Sokhan: 0000-0003-1860-3099 A,D,F

Yaroslava I. Burma: 0000-0003-1425-1372 ${ }^{C, E}$ 
Volodimir V. Pavlov: 0000-0002-6234-113X ${ }^{B}$

Oleksandr O. Goidenko: 0000-0003-0296-6936 ${ }^{B}$

Larisa I. Markush: 0000-0002-4516-2447 ${ }^{B}$

Hanna O. Spitsyna: 0000-0002-6677-6915 ${ }^{A, E}$

Liudmyla V. Kolesnyk: 0000-0003-4417-7759 ${ }^{A, C}$

\section{Conflict of interest:}

The Authors declare no conflict of interest.

\section{CORRESPONDING AUTHOR}

Anton V. Sokhan

Kharkiv national medical university

4 Nauki ave, 61022 Kharkiv, Ukraine

tel: +380979287238

e-mail:antonsokhan@gmail.com

Received: 27.04 .2020

Accepted: 23.11 .2020

A - Work concept and design, B - Data collection and analysis, C - Responsibility for statistical analysis,

$\mathbf{D}$-Writing the article, $\mathbf{E}$-Critical review, $\mathbf{F}$ - Final approval of the article 